\title{
Modelos Pedagógicos para Educação a Distância: pressupostos teóricos para a construção de objetos de aprendizagem
}

\author{
Dra.Patricia Alejandra Behar - NUTED/UFRGS -pbehar@terra.com.br \\ Dra.Liliana Passerino - CINTED/UFRGS- liliana@ cinted.ufrgs.br \\ Msc.Maira Bernardi - NUTED/UFRGS - mairaber@terra.com.br
}

\begin{abstract}
Resum:- O presente artigo apresenta uma discussão teórica em torno do conceito de modelo pedagógico para EAD e dos elementos que o compõem. Abordando elementos epistemológicos, propõe-se uma revisão do conceito de arquitetura pedagógica ampliando para o construto de modelo pedagógico. Esta discussão teórica constitui-se a base para a construção de um objeto de aprendizagem denominado ARQUEAD. Este visa ser um instrumento norteador na formação de professores para atuarem na modalidade à distância. Finalmente, apresenta-se o objeto de aprendizagem ARQUEAD desenvolvido pelo Núcleo de Tecnologia Digital aplicada à Educação (NUTED/UFRGS).
\end{abstract}

Palavras-chave: modelo pedagógico, educação a distância, objeto de aprendizagem

Título em inglês: Pedagogical Models for e-learning: theorical assumptions for construction learning object

Abstract: This paper presents a theoretical approach about pedagogical model for elearning and its components. From this approach we propose a revisited concept of pedagogical architecture for broaden concept of pedagogical model. This argued was foundation for construction process of learning object called ARQUEAD. This can be used as a tool for giving the marks in the teaching formation via e-learning. Finally, we present ARQUEAD learning object development at NUTED/UFRGS

Keywords: pedagogical model, e-learning, learning object

\section{Introdução}

Na última década, as Universidades Brasileiras estão passando por um processo de mudança muito significativo, no que se refere à introdução da educação a distância (EAD) no processo educacional. Pode-se dizer que está se vivendo um momento de transformação, onde os paradigmas presentes na sociedade já não estão dando mais conta das relações, necessidades e desafios sociais, e um novo modelo educativo está emergindo num processo ainda de construção. Está se rompendo com a idéia de uma sociedade centrada no trabalho para uma sociedade que dá valor à educação, dentro de uma nova totalidade, denominada em muitos contextos da Sociedade da Informação, ou ainda, em Rede. Portanto, se faz necessário investigar como está ocorrendo a passagem de uma Sociedade Industrial, que privilegia a cultura do ensino, para uma Sociedade em Rede, que dá ênfase a cultura da aprendizagem. Investigar quais são os elementos que se transformaram e continuam se transformando durante este período e quais entram em cena, ainda desconhecidos.

O modelo educativo vigente na sociedade Industrial privilegia o ensino tecnicista, tendo como função preparar os indivíduos para o desempenho de papéis, de acordo com suas aptidões. Neste modelo, toda prática pedagógica vivenciada não 


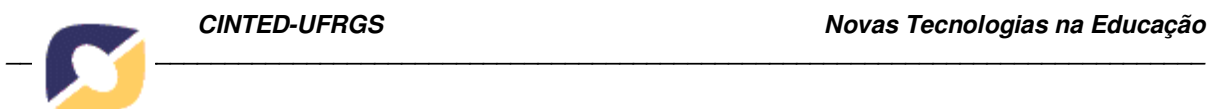

apresenta nenhuma relação com o cotidiano do aluno, pouco desperta a curiosidade, privilegiando o acúmulo de conhecimentos, valores e normas vigentes na sociedade de classe repassados de forma conteudista e desarticulada. Como resultado decorrente, o aluno passa a tornar-se desinteressado por não perceber o sentido daquilo que está sendo ensinado.

$\mathrm{Na}$ sociedade em Rede, aprender caracteriza-se por uma apropriação de conhecimento que se dá numa realidade concreta, isto é, parte da situação real vivida pelo educando apoiado na presença mediadora e gestora do professor compromissado com seus alunos e com a construção de conhecimentos, procurando responder ao princípio da aprendizagem significativa (Castells, 1999). Uma aprendizagem significativa pressupõe o oferecimento ao educando de informações relevantes, que possam ser relacionadas com os conceitos já ou pré-existentes em sua estrutura cognitiva e que acabam por influenciar na aprendizagem e no significado atribuído aos novos conceitos aprendidos.

Nesta perspectiva, o conhecimento é concebido como resultado da ação do sujeito sobre a realidade, estando o aluno na posição de protagonista no processo da aprendizagem construída de forma cooperativa numa relação comunicativa renovada e reflexiva com os demais sujeitos. Neste paradigma, a prática pedagógica considera o processo e as ações mais significativas que o produto deles resultantes.

Evidentemente que não é só por causa da introdução da Educação a Distância (EAD) que está ocorrendo uma crise paradigmática na educação, mas com ela fica mais evidente e clara a necessidade de realizar mudanças significativas nas práticas educacionais e, conseqüentemente, no modelo pedagógico. Portanto, pode-se dizer que um novo espaço pedagógico está em fase de gestação, cujas características são: o desenvolvimento das competências e habilidades, respeito ao ritmo individual, a formação de comunidades de aprendizagem, redes de convivência (Behar, 2005). Será preciso dar foco à construção, à capacitação, à aprendizagem, a educação aberta e à distância, na gestão do conhecimento. Assim, conceitos como construção do conhecimento, autonomia, autoria, interação, construção de um espaço heterárquico, de cooperação, respeito mútuo, solidariedade; centrado na atividade do aprendiz, identificação e solução de problemas passam a ser os alicerces deste novo modelo que está emergindo.

É neste contexto que a EAD entra em cena para auxiliar a resolver os problemas da educação superior brasileira. Com o uso de ferramentas tecnológicas para a geração do ensino remoto, governo, entidades públicas e privadas esperam romper o gigantesco déficit educacional e encontrar o caminho da inclusão digital na Sociedade da Informação.

Logo, vê-se que esta modalidade tem instrumentos capazes de transformar a educação brasileira, com o uso das tecnologias de informação e comunicação (TIC). Acredita-se que, sem o uso intensivo de tecnologia, as universidades brasileiras não terão condições de atingir todo o seu leque de formação/capacitação na educação superior.

Existe uma expectativa muito grande em torno da EAD principalmente no ensino superior como se pode constatar através dos programas criados pelo Ministério da Educação, através da sua Secretaria de Educação a Distância (SEED/MEC), que vem gerenciando ações de âmbito nacional para a inserção da inovação tecnológica nos processos de ensino e aprendizagem como uma das estratégias para democratizar e elevar o padrão de qualidade da educação brasileira. Estas ações e programas visam promover o desenvolvimento e a incorporação das TIC e das técnicas de educação à distância aos métodos didático-pedagógicos convencionais. Além disso, a SEED 
incentiva a pesquisa e o desenvolvimento, voltados para a construção de novos conceitos e práticas nas instituições públicas brasileiras, desenvolvendo vários programas e projetos. Entretanto, para que isto realmente venha a ser uma das saídas, há necessidade de se construir um modelo consistente, com pilares bem estruturados, no que se refere aos seus aspectos epistemológicos, pedagógicos, organizacionais, tecnológicos e metodológicos. Logo, está se falando de um possível modelo pedagógico, mas qual é o real significado deste termo?

Assim neste artigo, parte-se para uma discussão acerca dos "possíveis" elementos que fazem parte dos modelos pedagógicos emergentes desta modalidade. A partir destes está sendo construído um objeto de aprendizagem para ser utilizado como instrumento norteador da aplicação de modelos pedagógicos na formação de professores para atuar em cursos de educação a distância.

\section{Conceito de modelo pedagógico: alicerces para uma conceituação científica}

A atividade científica procura compreender, explicar e predizer fenômenos do mundo. Por esse motivo, a ciência busca através de leis, princípios e modelos generalizar e simplificar a realidade. O conceito de modelo surge, portanto, com o viés de estabelecer uma relação por analogia com a realidade. O modelo é um sistema figurativo que reproduz a realidade de forma mais abstrata, quase esquemática e que serve de referência. Do exposto deduz-se rapidamente que modelos são construtos sociais criados com a finalidade de expor a diferentes situações hipotéticas que permitam "interpretar a realidade", visto que a mesma é inapreensível enquanto objeto, pois a realidade é uma construção social (Berger; Buckmann, 1966).

O conceito de modelo é um dos conceitos científicos mais importantes que alicerçam a atividade cientifica permitindo comparar, simular e compreender fenômenos a partir dos seus modelos. Um modelo é uma representação mental compartilhada de um conjunto de relações que definem um fenômeno que visa a melhor compreensão do mesmo.

$\mathrm{Na}$ educação o conceito de modelo foi erroneamente considerado sinônimo de teorias de aprendizagem como as desenvolvidas por Piaget, Vygotsky, Wallon, Roger, entre outros ou como metodologia de ensino. Embora um modelo pedagógico possa ser embasado numa ou mais teorias de aprendizagem, de forma geral os modelos são "reinterpretações" de teorias a partir de concepções individuais dos professores que se apropriam parcial ou totalmente de tais construtos teóricos imbuídos num paradigma vigente. Desta forma, o modelo construído muitas vezes recebe o nome de uma teoria (piagetiana, rogeriana, etc.) ou de um paradigma (construtivista, interacionista, etc.) sem contanto, ter propriamente sua epistemologia embasada nos mesmos paradigmas ou teorias mencionados.

Na Figura 1 apresenta-se o processo de construção dos modelos. Parte-se de um paradigma dominante que, em geral influencia as teorias de aprendizagem vigentes, assim como outras teorias cientificas. A partir deste, os sujeitos constroem um modelo pessoal próprio que é compartilhado com os pares gerando, assim, um modelo pedagógico compartilhado.

Muitas vezes, percebe-se que o termo modelo pedagógico é interpretado como metodologia de ensino, que sem dúvida é um dos elementos do mesmo, como irá ser apresentado na próxima seção. Mas esta "redução" do modelo à sua parte visível ignora outros elementos que o constituem e que são fundamentais de serem explicitados para a compreensão do processo educativo, principalmente, na formação de professores. 


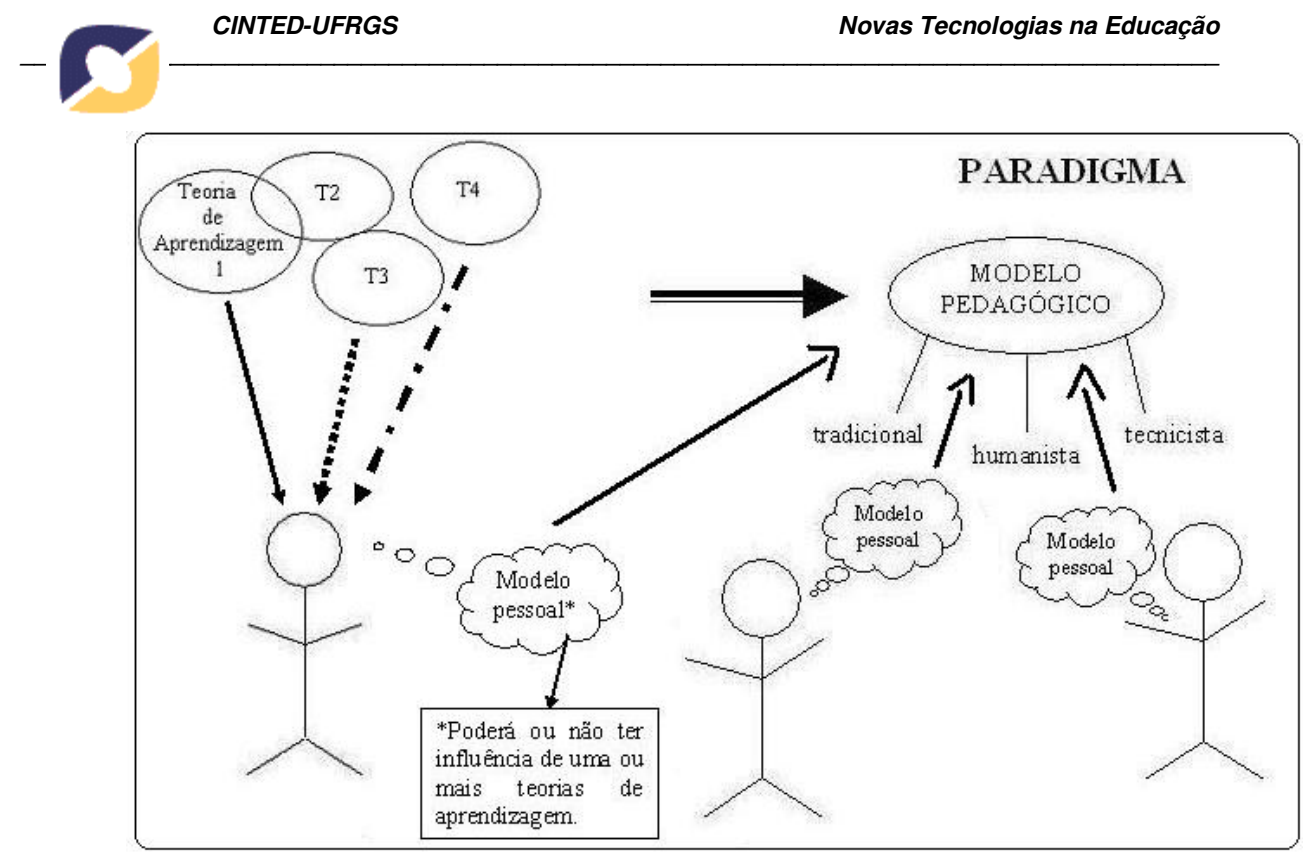

Figura 1: Construção de Modelos Pedagógicos

Na Educação a Distância (EAD), a situação fica mais complexa ao se estabelecer um novo patamar para a palavra modelo, vinculada fortemente às tecnologias da informação e comunicação e, particularmente, às plataformas e/ou ambientes virtuais de aprendizagem (AVA's) utilizados como forma de mediação para promover a educação.

Assim, é comum ler em artigos científicos frases como "o modelo de EAD implantado aqui é o de vídeo-conferência" ou "nosso modelo de EAD busca a aprendizagem colaborativa através da interação aluno-professor" ou os "modelos" propostos são apresentados segundo a perspectiva das trocas comunicativas e assim por diante. Frente a esta situação questiona-se até que ponto o termo modelo pedagógico tem uma conceituação clara na área de informática na educação e, em especial, na educação a distância.

Vê-se com preocupação a profusão do termo modelo pedagógico para significar qualquer conceito, e por isso, o presente artigo visa alicerçar a construção de um significado mais aprimorado do termo modelo pedagógico vinculado à educação a distância.

Neste estudo, por serem estabelecidas as bases teóricas do conceito de modelo, depara-se com escassez de bibliografia e, paralelamente, uma grande quantidade de bibliografia sobre formação de professores e sobre EAD que não abordam, exatamente, a questão em discussão. A partir de estudos sobre metodologia, currículo, teorias de aprendizagem e desenvolvimento cognitivo define-se modelo pedagógico como um sistema de premissas teóricas que representa, explica e orienta a forma como se aborda o currículo e que se concretiza nas práticas pedagógicas e nas interações professoraluno-objeto de conhecimento. Nesse triângulo (professor, aluno e objeto) é estabelecida uma relação triádica de atenção conjunta ${ }^{1}$ e na qual o modelo concretiza-se

\footnotetext{
${ }^{1}$ Cenas de atenção conjunta são interações sociais nas quais os sujeitos prestam conjuntamente atenção a uma terceira pessoa ou objeto por um período de tempo. Não são apenas cenas perceptuais, pois focam alguns aspectos do mundo perceptual, não são meramente eventos lingüísticos, pois contém mais coisas do que é explícito nos símbolos lingüísticos. Numa cena de atenção conjunta os sujeitos precisam se identificar como agentes intencionais, ou seja, cenas de atenção conjunta são definidas intencionalmente ao "... fornecer o contexto intersubjetivo em que se dá o processo de interação" (Tomasello, 2003).
} 
em ação e estabelece um contexto intersubjetivo construído a partir da subjetividade de cada participante compartilhando uma definição de situação determinada ${ }^{2}$.

Esse sistema de premissas teóricas, denominado de modelo pedagógico, contempla um recorte multidimensional das variáveis participantes, seus elementos, que será abordado a seguir.

\section{Elementos de um modelo pedagógico para EAD}

Ao tratar da construção de um modelo pedagógico voltado para a EAD, entendese que seja necessário definir seus elementos. Partindo da concepção anteriormente citada, enfatiza-se que o modelo pedagógico traz consigo uma estrutura calcada sobre uma determinada concepção epistemológica e, em consonância, com uma ou mais teorias educacionais a serem utilizadas como eixo norteador da aprendizagem.

Esta estrutura é denominada de modelo pedagógico como é mostrado na Figura 2 e traz no seu cerne um elemento que denominamos de arquitetura pedagógica (AP). Esta é constituída do (1) fundamentação do planejamento/proposta pedagógica (aspectos organizacionais): onde estão incluídos os propósitos da aprendizagem, organização do tempo e do espaço e expectativas na relação da atuação dos participantes ou da também chamada organização social da classe, (2) conteúdo materiais instrucionais e/ou recursos informáticos utilizados - objetos de aprendizagem, software e outras ferramentas de aprendizagem - (3) atividades, interações, procedimentos de avaliação e a organização de todos esses elementos numa seqüência didática para a aprendizagem (aspectos metodológicos); (4) definição da plataforma de EAD e suas funcionalidades (aspectos tecnológicos).

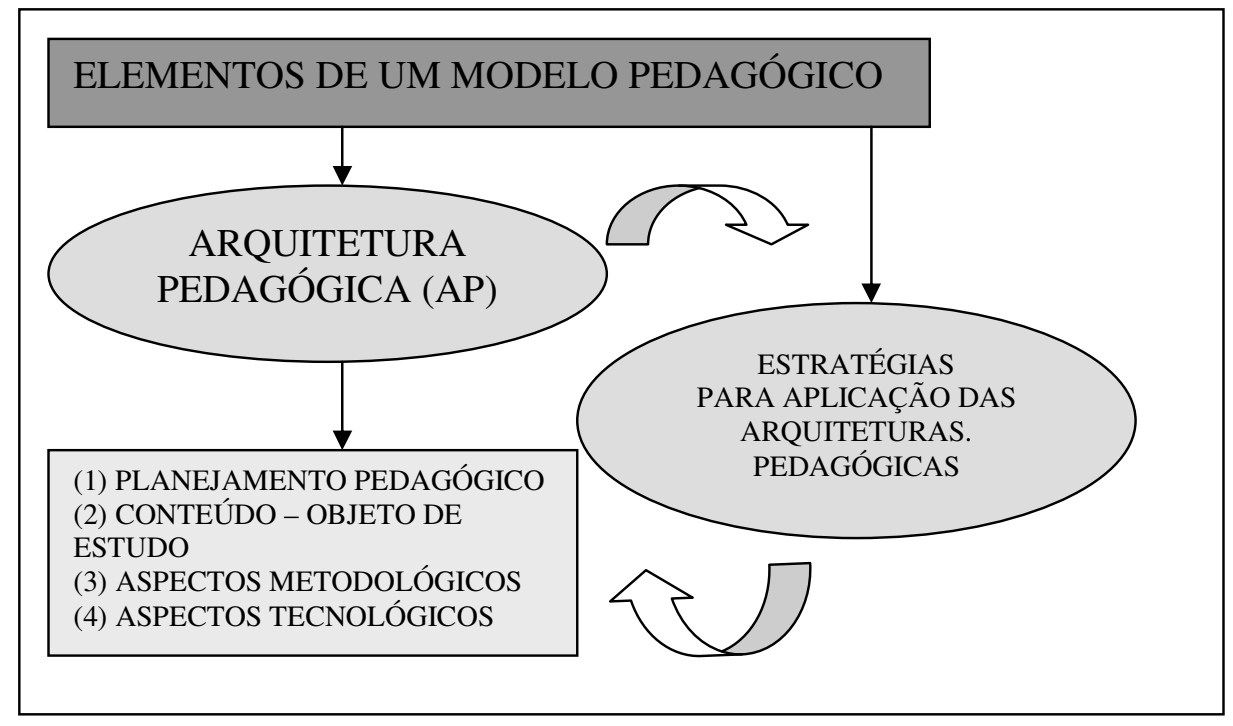

Figura 2: Elementos de um modelo pedagógico

Os aspectos organizacionais dizem respeito à definição dos objetivos da aprendizagem em termos de "lista de intenções"; a organização social da classe na qual se estabelecem agrupamentos e separações, definição de papéis, direitos e deveres de cada agente (seja este aluno ou professor); a organização do tempo e do espaço levando

\footnotetext{
${ }^{2}$ Uma definição de situação é a forma como se representam e significam objetos e eventos numa situação (Wertsch, 1999).
} 


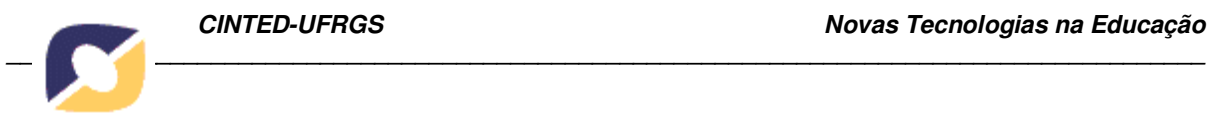

em conta, particularmente, as questões que a virtualidade propicia em termos de flexibilização. Segundo Zabala (1998) as variáveis tempo/espaço são, em geral, pouco explicitadas nos modelos pedagógicos, mas tornam-se elementos fundamentais em qualquer espaço de intervenção pedagógica. Na educação presencial estas duas variáveis "parecem" imutáveis na organização escolar já que tempos (organizados como períodos) são fixos assim como salas de aula, porém na EAD eles tomam dimensões que ainda precisam ser mais exploradas nas práticas educativas dos professores que trazem suas concepções de uma educação presencial muito arraigada.

Com relação aos aspectos de conteúdo, entendemos que materiais instrucionais, objetos de aprendizagem e outros elementos, especialmente, utilizados com a finalidade de apropriação do conhecimento são relativos ao tipo de conteúdo que se pretende trabalhar (conceitual, fatual, atitudinal, procedimental) de acordo com uma das classificações aceitas na educação (Zabala, 1998). Esse conjunto de elementos deve ser cuidadosamente planejado para que a partir deles seja possível construir conhecimento, desenvolver capacidades, habilidades, competências.

Os aspectos metodológicos e tecnológicos tratam não somente da seleção das técnicas, procedimentos e dos recursos informáticos a serem utilizados na aula, mas também da relação, articulação e estruturação que a combinação destes elementos terão. Esta vai depender dos objetivos a serem alcançados e da ênfase dada aos conteúdos previamente estabelecidos. Logo, a ordem e as relações constituídas determinam, de maneira significativa, o modelo e as características de uma aula. Esta ordem denominase sequiência didática ou de atividades e, a partir da análise de diferentes seqüências, podem ser estabelecidas as características diferenciais presentes na prática educativa.

É importante ressaltar que a seqüência didática é um dos elementos da arquitetura diferenciando-se das estratégias para aplicação das AP's que constituem a dinâmica do modelo pedagógico, a seguir explicitada.

Dentre os aspectos tecnológicos, tem-se a Plataforma ou Ambiente Virtual de Aprendizagem (AVA). Considera-se um AVA como ambiente coletivo que favorece a interação dos sujeitos participantes, sendo este um todo constituído pela plataforma e por todas as relações estabelecidas pelos sujeitos usuários a partir do uso das ferramentas de interação, tendo como foco principal a aprendizagem. O AVA é um espaço na Internet formado pelos sujeitos e suas interações e formas de comunicação que se estabelecem através de uma plataforma. Entende-se por plataforma uma infraestrutura tecnológica composta pelas funcionalidades e interface gráfica que compõe o AVA (Behar, 2006).

Entende-se que as estratégias para aplicação das arquiteturas pedagógicas é que dão a dinamicidade às mesmas, ao permitir que uma determinada arquitetura possa contemplar diferentes estratégias de ação.

Nesta perspectiva, entende-se que a estratégia de aplicação é um ato didático que aponta à articulação e ajuste de uma arquitetura para uma situação de aprendizagem determinada (turma, curso, aula). Mantendo-se fiel à matriz estruturante de uma arquitetura determinada, as estratégias de aplicação construídas para a aprendizagem, correspondem a um plano que se constrói e reconstrói através de processos didáticos permeados pelas variáveis educativas que dão o caráter multidimensional ao fenômeno. Assim o professor poderá ir evidenciando, na própria estruturação, estratégias das mais diversas a fim de atingir resultados mensuráveis que, por um lado, se manifestarão no processo de aprendizagem dos seus alunos e, por outro, poderão resultar na modificação/adaptação da arquitetura definida a priori. 


\section{A construção de um objeto de aprendizagem ARQUEAD - ARQUiteturas pedagógicas para formação de professores no contexto da Educação À Distância}

De forma a contemplar o estudo teórico, propõe-se a elaboração de um objeto de aprendizagem (OA) para a formação de professores, denominado ARQUEAD Arquiteturas Pedagógicas para EAD. O objetivo, portanto foi construir material digital em forma de vídeos, textos, som, animação, entre outros para dar suporte à construção dos termos abordados nas seções acima: teorias da aprendizagem, epistemologias, paradigma educacional, entre outros. Visa-se, assim, apoiar o processo de formação ou auto-formação de professores com diferentes mídias integradas ao objeto. Portanto, o objetivo principal deste objeto é oferecer subsídios aos professores para que estes possam construir seu próprio modelo pedagógico a ser aplicado na Educação a Distância. Logo, nesta seção são apresentados os passos para a construção deste instrumento norteador, passando desde sua concepção, planificação em forma de storyboard, implementação e finalmente sua validação/avaliação.

Assim, este objeto pretende realizar um embasamento teórico-prático sobre o modelo pedagógico para formação de professores no contexto da EAD. Dentre os principais conceitos a serem discutidos, destacam-se:

(1) Arquiteturas Pedagógicas (AP's) e seus componentes: proposta pedagógica (aspectos organizacionais); conteúdo; atividades, interações, procedimentos de avaliação (aspectos metodológicos); plataforma e suas funcionalidades (aspectos tecnológicos);

(2) Princípios da didática de EAD;

(3) Diferentes concepções epistemológicas para as arquiteturas pedagógicas;

(4) Projetos de aplicabilidade das AP's em EAD.

Logo, abordam-se, em diversos tipos de mídias, as diferentes correntes pedagógicas/epistemológicas, a utilização de funcionalidades/recursos/ferramentas de ambientes virtuais de aprendizagem (AVA's) de acordo com a metodologia do professor, o conteúdo trabalhado e a construção das AP's resultantes desta combinação, ou seja, a prática pedagógica em EAD. Assim, será possível subsidiar o planejamento pedagógico na modalidade de EAD dos professores, trazendo experiências de sala de aula para o virtual. O objeto apresentará a diversidade de funcionalidades disponíveis nos principais AVA's, semelhanças/diferenças entre as ferramentas disponibilizadas através das tecnologias digitais, salientando diferentes possibilidades pedagógicas de uso numa atividade em EAD. Todas as ferramentas utilizadas e referenciadas no objeto estarão disponíveis tanto na Web quanto em conexão off-line.

Destacam-se como características principais, a vinculação deste objeto com as disciplinas de graduação, pós-graduação, Pedagogia a Distância, cursos REGESD ${ }^{3}$ e UAB (Universidade Aberta do Brasil), cursos de capacitação em EAD promovidos na

\footnotetext{
${ }^{3}$ REGESD - Rede Gaúcha de Ensino Superior à distância. A REGESD é uma parceria formada entre Instituições de Ensino Superior (IES), a Secretaria Estadual e as Secretarias Municipais de Educação do Estado do Rio Grande do Sul que tem como objetivo otimizar o compartilhamento de recursos humanos e de recursos materiais, na oferta de cursos de licenciatura na modalidade EAD. A REGESD faz parte do Projeto Pró-Licenciaturas do MEC, que objetiva a participação junto a rede de Universidades do RS na elaboração e oferta de Cursos de Licenciaturas para professores que atuam no ensino fundamental público.A Rede Gaúcha de Ensino Superior à Distância foi composta por oito Instituições de Ensino Superior (IFES), que oferecerão os nove cursos de graduação citados acima. São elas: UFRGS, UCS, UFSM, UNISC, FURG, UERGS, UFPEL e CEFET - RS.
} 


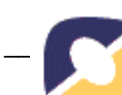

modalidade extensiva e as disciplinas de instrumentalização em EAD e TIC. Este objeto foi construído em módulos, sendo possível agregá-lo todo ou, parcialmente, a outros objetos e/ou ambientes de aprendizagem. O objeto também apresenta um manual específico de utilização, destacando seus aspectos relacionados às diferentes teorias e propostas metodológicas, bem como, as diferentes formas de construir arquiteturas pedagógicas.

Para desenvolvimento do mesmo, consideraram-se tanto os aspectos educacionais quanto estéticos e tecnológicos. Assim, pretende-se oferecer ao usuário uma ferramenta de fácil navegação e agradável experiência estética, de forma que os objetivos educacionais possam ser atendidos.

O ARQUEAD foi desenvolvido, como já foi citado, em quatro etapas principais: concepção do projeto, planificação, implementação e avaliação, seguindo os critérios necessários para o desenvolvimento de objetos de aprendizagem. A seguir, são descritos os caminhos percorridos para o desenvolvimento do mesmo.

1) Concepção do projeto: Nesta etapa são definidas as linhas mestras e a aplicação que se pretende desenvolver para o OA partindo da idéia inicial construída pelo grupo de pesquisadores. Nesta primeira etapa, também são estabelecidos os pressupostos teóricos dos conceitos abordados anteriormente, relacionando com os principais objetivos previstos para o ARQUEAD.

2) Planificação: No período de Planificação realizou-se a pesquisa para o desenvolvimento do OA, o estudo do storyboard (Figura 3) e da navegação, com estrutura não-linear. Também foram pesquisados os tipos de recursos que disponibilizará cada objeto (textos, vídeos, imagens, etc.), a metáfora visual e o desenho da interface.

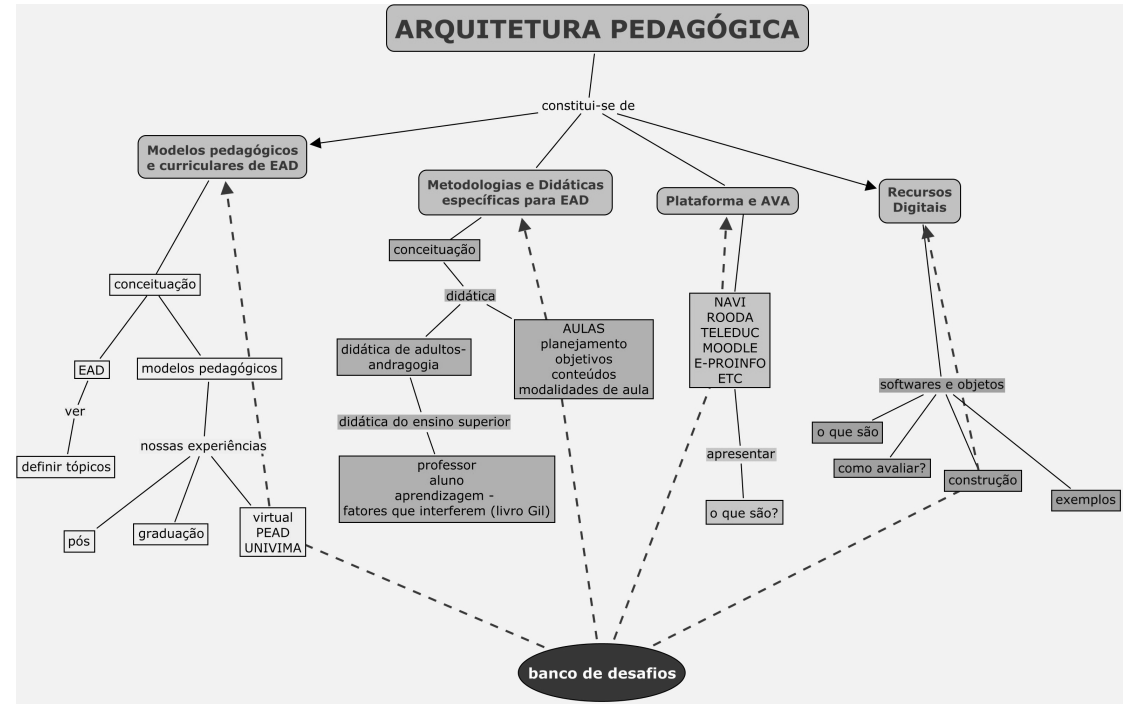

Figura 3: Mapeamento dos conteúdos do objeto ArquEAD

Nesta etapa foi realizado o levantamento de textos e sites da web para serem contemplados na biblioteca do ARQUEAD, construídos alguns textos enfocando a didática da EAD, exemplos de como escolher, elaborar material didático e uso de recursos para uma aula virtual e como avaliar tais experiências.

3) Implementação: esta fase se refere ao desenvolvimento propriamente dito, na qual é definido o tipo de programação que será utilizada e foram elaborados os dois protótipos do objeto até alcançar a sua versão final. 


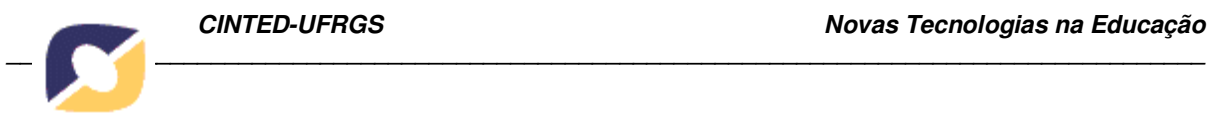

O objeto foi desenvolvido em Adobe Flash 8, Autocad e Autodesk 3D Studio MAX. Estes softwares possuem ferramentas que possibilitam a utilização de animações e recursos interativos. Nesta etapa foi feito o estudo dos cenários para compor a interface gráfica dos objetos, dentro dos padrões de design da interação, informação e apresentação.

O design de informação refere-se aos materiais hipermidiais, tais como: material de apoio do em vídeo, áudio, som, animação, hipertextos, entre outros. Também há uma preocupação com os critérios de usabilidade na apresentação dos objetos, a fim de promover/implementar recursos de interatividade. Dentre os recursos de interação, entende-se o planejamento de atividades abertas/desafiadoras, a fim de promover ações/comunicação entre os professores, alunos e tutores, que os levem à construção do conhecimento.

Foram elaborados dois protótipos, com diferentes tipos de animação até a definição da versão final. O primeiro protótipo mostrado na Figura 4 caracterizou-se dentro de uma estrutura pedagógica estática e de pouca interação que não atendia a proposta inicial por estar refletindo uma prática instrucionista de educação. Isto comprometia seu uso dentro de uma proposta mais dinâmica e significativa. Logo, faltava atender os critérios de usabilidade e de uma interface agradável e convidativa ao trabalho.

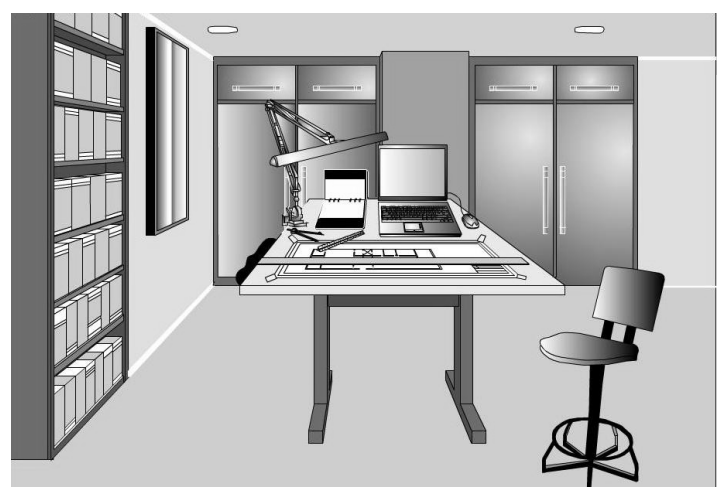

Figura 4: Protótipo I - Tela estática, pouca interação.

Já no novo protótipo de uma das cenas do ARQUEAD, como mostra a Figura 5, atendeu-se a tais critérios ao simular situações cotidianas de um professor que inicia suas atividades na área de EAD. Estas simulações são animadas, como se fosse a seleção de cenas de um filme. Tal formato possibilita uma maior interação entre o usuário e o objeto de aprendizagem, devido a identificação proporcionada pelo personagem "Professor". Dentre as cenas construídas, o personagem passa por situações de dificuldade na familiarização dos recursos informáticos, no planejamento e nas metodologias possíveis em uma sala virtual, sendo que o usuário do objeto será convidado a procurar soluções para as situações apresentadas participando de palestras virtuais, resolvendo os desafios, lendo textos, entre outros recursos que o objeto disponibiliza. 


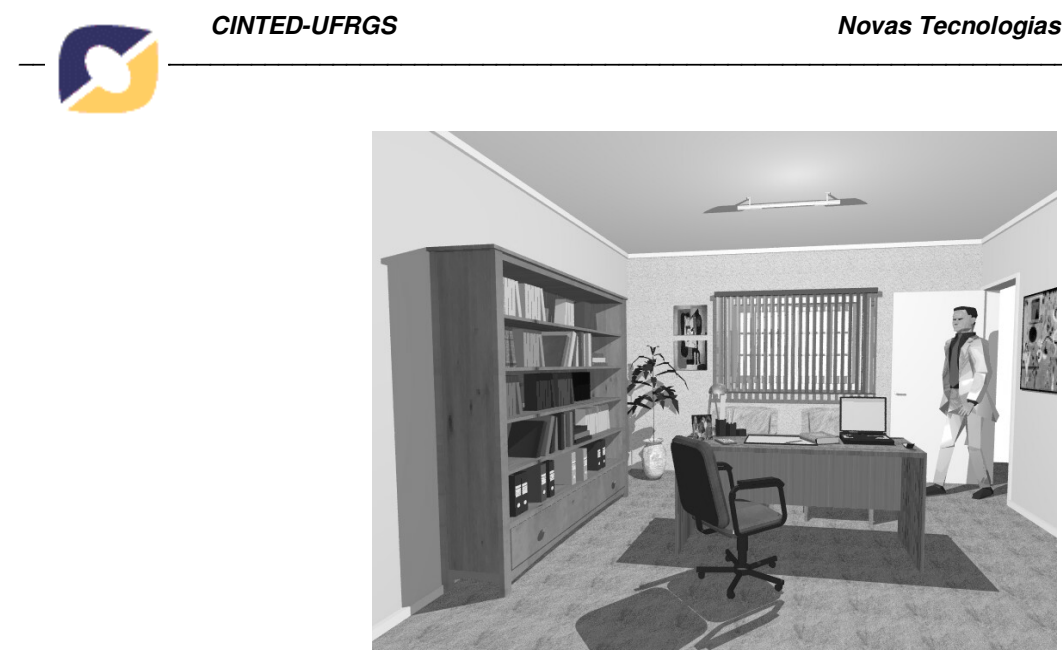

Figura 5: Cena do objeto ArquEAD

4) Avaliação: Esta fase consiste em testar o funcionamento do objeto, seu grau de adequação ao público-alvo e o nível de cumprimento dos objetivos.

As etapas de construção do objeto foram realizadas de forma cíclica, ou seja, passaram por uma análise da programação, design, teste e validação, para que posteriormente seja realizada a reestruturação dos recursos dos OA's até chegarem em um nível de funcionamento estável e serem o mais intuitivos possíveis para os seus usuários.

Atualmente, estão sendo testados os cenários compostos para a interface gráfica dos objetos e sua integração com os demais recursos utilizados de textos, apresentação de slides e vídeos construídos, dentro dos padrões anteriormente citados prevendo a validação junto a usuários a partir de 2008 nos cursos de formação de professores em EAD da UFRGS junto à Secretaria de Educação à Distância (SEAD)/UFRGS.

\section{Considerações Finais}

Na presente abordagem foi apresentada uma delimitação "possível" para o conceito de modelo pedagógico, concebendo-o como representações compartilhadas do sistema de relacionamentos estabelecidos na atividade pedagógica. Foram analisados seus elementos constitutivos com ênfase na construção da arquitetura pedagógica e das variáveis que a compõem. Com esta abordagem, foi elaborado um objeto de aprendizagem com o objetivo de abordar as diferentes correntes pedagógicoepistemológicas, o uso dos recursos informáticos e as possíveis ações do professor no contexto de EAD. Entende-se que, este objeto poderá auxiliar o professor a explicitar o modelo pedagógico a partir da construção da sua arquitetura e da identificação das estratégias de aplicação possíveis. Neste sentido, prevê-se como trabalho futuro, o aperfeiçoamento do ARQUEAD com a implementação de um banco de dados que armazene diferentes arquiteturas construídas pelos professores de diversas áreas de atuação e suas estratégias de aplicação.

\section{Referências Bibliográficas}

BEHAR, P. A.; LEITE, Silvia Meirelles. Criando novos espaços pedagógicos na Internet: o ambiente ROODA. In: WWW/Internet 2005, 2005, Lisboa. Anais do. Lisboa: IADIS. v. 1. p. 3-10, 2005.

BEHAR, Patricia Alejandra; Leite, Silvia Meirelles. The Virtual Learning Environment ROODA: An Institutional Project of Long Distance Education. Journal of science education and technology, EUA, v. 15, n. 2, p. 159-167, 2006. 
BERGER, P. \& LUCKMANN, T. The Social Construction of Reality. Garden City: Double-day, 1966.

CASTELLS, Manuel. A Era da Informação: economia, sociedade e cultura. vol. 3, São Paulo: Paz e terra, 1999.

TOMASEllo, M.. Origens Culturais da Aquisição do Conhecimento Humano. São Paulo: Marins Fontes. (Tópicos Collection), 2003.

WERTSCH, J. La Mente en Acción. Buenos Aires: Aique, 1999.

ZABALA, Antoni. A prática educativa: como ensinar. Porto Alegre: ArtMed, 1998. 